Wayne State University

\title{
DigitalCommons@WayneState
}

Teacher Education Faculty Publications

Teacher Education

4-1-2006

\section{Gaining Options: A Mathematics Program for Potentially Talented At-risk Adolescent Girls}

Pamela Trotman Reid

Roosevelt University

Sally K. Roberts

Wayne State University, s.k.roberts@wayne.edu

\section{Recommended Citation}

Reid, P. T., \& Roberts, S. K. (2006). Gaining options: A mathematics program for potentially talented at-risk adolescent girls. MerrillPalmer Quarterly, 52(2), 288-304. doi:10.1353/mpq.2006.0019

Available at: http://digitalcommons.wayne.edu/coe_ted/4 


\section{Gaining Options: A Mathematics Program for Potentially Talented At-risk Adolescent Girls}

Pamela Trotman Reid, Roosevelt University

Sally K. Roberts, Wayne State University

In response to indicators that a decline in interest in mathematics occurs among girls-particularly those from low-income and minority groups--during middle school, the GO-GIRL (Gaining Options: Girls Investigate Real Life) program was designed to help potentially talented at-risk girls. The program aimed to build mathematical confidence, skills, and conceptual understanding by integrating mathematics and social science research in a single-sex, technology-rich environment supported by university student mentors. The program targeted seventh-grade urban girls from public and private schools. Participants met over the course of ten Saturdays to learn research methods, computer skills, mathematics, and descriptive statistics. Quantitative data from the girls indicate that participants demonstrated greater confidence in their mathematics ability and increased mathematics achievement after the program. Qualitative data confirmed these findings and supported the contention that multiple factors play a role in fostering girls' interest in studying mathematics and science.

Research on gender and ethnic bias chronicles declines in American students' attitudes toward and achievement in mathematics and science, both from the 1960s to the present and from the early grades to high school (Eccles, 1997; Riley, 1997). Indeed, the drop in achievement and interest

Pamela Trotman Reid, Provost and Executive Vice President; Sally K. Roberts, Teacher Education Division.

The project described in this article was supported in part by the National Science Foundation (Grant No. 0114683). We are grateful for the assistance and support of our colleagues and students at the University of Michigan Institute for Research on Women and Gender and at the Wayne State University College of Education. We also appreciate the participation of all the girls, families, and teachers.

Correspondence should be directed to Pamela T. Reid, Office of the Provost, Roosevelt University, 430 S. Michigan Avenue, Chicago, II 60605. E-mail: preid@roosevelt.edu

Merrill-Palmer Quarterly, April 2006, Vol. 52, No. 2, pp. 288-304. Copyright $\odot 2006$ by Wayne State University Press, Detroit, MII 48201. 
from the early grades to high school is greater for female and minority students than for other students. This is particularly troublesome given research showing that students' subjective task-values of subject matter influence achievement-related behaviors such as performance and course selection (Eccles et al., 1983). While various researchers have shown that interest and achievement in mathematics and science are comparable before middle school (Brush, 1979; Gilbert, 1996), by eighth grade there are differences by sex and ethnicity for interest in, achievement in, and aspirations for fields that depend on mathematics (Bae, Smith, Pratt, \& National Center for Education Statistics, 1997; Campbell, 1995).

Differential interest in mathematics between male and female students is found among students participating in science, mathematics, and engineering summer camps (J. D. Lee, 1998). By high school, girls and minority students, to a much greater extent than boys and White students, self-select out of higher-level, "academic track" mathematics and science courses such as calculus and chemistry (Clewell, Anderson, \& Thorpe, 1992). Gender gaps and ethnic differences also persist through high school on "high stakes" tests such as the SAT and statewide achievement tests. Many African American, Latino, and Native American girls consistently score below many White girls (College Board Online, 1997). To narrow these gaps and ensure success for all students, interventions need to reach and encourage girls, especially those from ethnic minority backgrounds, before they enter high school.

\section{Gender Gaps in Mathematics and Science}

The increased demand for sophisticated technological skills in the workplace underscores the importance of educating all students to high levels of scientific, mathematical, and technological literacy, yet women continue to be underrepresented in mathematics, science, and engineering careers in the United States. The National Science Foundation issued a report in 2000 that examined participatory changes in these fields, using the most recent data available (from 1997). That year, while females comprised $46 \%$ of the total U.S. labor force, only $22.8 \%$ of all scientists and engineers were women. Further, within these fields, women were concentrated in the life and social sciences, with females comprising $63 \%$ of all psychologists and $42 \%$ of biologists, compared with $10 \%$ of physicists and astronomers and 9\% of engineers (National Science Foundation, 2000).

Gender differences in participation and performance also exist at the undergraduate level (Hill, 2002). Interestingly, the differential participa- 
tion occurs despite similar course-taking patterns in high school for many higher-level mathematics and science courses, such as calculus and chemistry (National Science Board, 2003). Although some might argue that the gender gap is relatively small, the differences in the average SAT-M scores of Talent Search boys and girls translate into sex differences in the composition of the accelerated summer courses, which indicates that proportionately fewer girls qualify as the cutoff rises (Rebhorn \& Miles, 1999).

Some researchers have concluded that differential performance on high-stakes tests despite similar course-taking might suggest differences in ability to do abstract mathematics. However, other research findings suggest that factors such as the instructional approach (Hoffmann \& Haussler, 1998), parents' and teachers' expectations of females versus males (Eccles et al., 1983; Gavin \& Reis, 2003), and personal belief systems (e.g., confidence, attribution style, belief in usefulness of mathematics) contribute to these differences (Fennema, 1996; Wigfield \& Eccles, 2002). Whatever factors may operate, it is clear that the majority of the students who enter postsecondary education will be required to study college-level mathematics, with mathematics as a discipline serving as a "filter" to success regardless of choice of college major (National Research Council, 1989).

The middle school years are particularly important for addressing gender differences in interest and confidence for mathematics and science. For girls the drops in these areas occur before actual academic grades or achievement test scores decline. For this reason, our project focuses on these school years. Seventh-grade girls firmly located in middle school are situated at a critical developmental stage with respect to their biological maturation. Additionally, these girls often experience significant changes with respect to their social roles in the family and with peers.

\section{Intervention Domains}

Role models and mentors. Over the years, the lack of women in advanced scientific arenas means few role models or mentors exist for girls and young women (Eccles, 1984; Kardash, 2000; Kota, 2001; Leder, 1992). In response to the many factors impeding girls' development in mathematics and sciences, a mathematics program was developed to include role models for adolescent girls. The opportunity to interact with role models who could encourage and inspire an interest in mathematics was seen as critical. Female scientists were invited to meet with girls, to lecture to them, and to provide them with stories of their own career development from girlhood to scientist status. The program we developed also included female mentors - that is, university students with competencies in math and science. The student mentors served as teachers to help 
the girls develop an interest in and comfort with mathematics and scientific reasoning.

Curricular developments. Gender gaps in mathematics have also been addressed through curricular changes. For example, nationally supported programs have developed new approaches to teaching mathematics and sciences to girls (National Science Foundation, 2000, 2002), course materials have been designed to directly address girls' interests, classroom strategies have been developed to enhance girls' participation, and attention has been directed toward enhancing girls' self-esteem (Cooper, Hall, \& Huff, 1991; Sprinthall \& Scott, 1989). Each single strategy has met with some success, yet an optimal intervention may require more than one shift in the learning environment. One successful effort was a pilot program, Using Mathematics: Girls Investigate Real Life (UM-GIRL), which Reid and Stewart developed as a summer program (2002). This intervention program employs multiple factors operating simultaneously to enhance the learning intervention.

\section{Potentially Talented At-risk Girls}

Given the challenges existing in schools and in society, it may be said that all girls are at risk for failing to develop interest in mathematics and science. As previously indicated, the challenges are even greater for African American and Latino girls and also for White girls from low-income families. It may also be inferred that single-parent families-that is, families experiencing divorce or separation-offer additional risk factors for educational problems and serve to exacerbate adolescent struggles with gender roles and career explorations.

The primary goal of our intervention program, therefore, was to engage at-risk girls who were potentially talented in mathematics. The program was intended to increase their feelings of competency in mathematics and thereby increase their persistence in math-related courses. Our decision was grounded in research reporting that even talented girls do not achieve their potential in mathematics. Other researchers corroborate the notion that many mathematically talented females perform at levels that are not commensurate with their abilities (Kusimo, Carter \& Keyes, 1999; Reis, 1987; Reis \& Callahan, 1989). The program ultimately was intended to increase the likelihood that girls will pursue math-related career options.

\section{Program Description}

Faculty and staff from two research universities collaboratively developed the program Gaining Options: Girls Investigate Real Life (GO-GIRL), a 
GO-GIRL Day by Day

Day 1: Introduction to GO-GIRL and Inquiry Process

Day 2: Ethical Research and Asking Research Questions

Day 3: Writing Survey Questions

Day 4: Introduction to Descriptive Statistics and Field Trip to Undergraduate Library

Day 5: Descriptive Statistics and Using the Graphing Calculator

Day 6: $\quad$ Field Trip to University of Michigan

Day 7: $\quad$ Types of Graphs and Using Graphs to Answer Research Questions

Day 8: Making Inferences, Communicating Results, and Field Trip to WSU School of Pharmacy

Day 9: Putting It All Together: Working on Final Projects

Day 10: Presentation of Final Projects and GO-GIRL Graduation

Figure 1. Typical schedule for the 10-week sessions

math enrichment program for seventh-grade girls. Based on several years of experience (Reid \& Stewart, 2002), it was expected that linking mathematics activities to the social sciences research methods would engage girls' interest. Thus, an intervention program was designed to include role models and university student mentors to encourage student success as measured by a skills test, persistence in the program, and attitudes toward mathematics.

The program activities were held across ten consecutive Saturdays on the campus of a major research university. Parents were responsible for transporting girls to the program site, where participants received snacks and lunch free of charge. Girls were given graphing calculators to use and keep upon program completion. During the program the participants utilized a laptop computer laboratory and had the opportunity to tour several campus sites.

Each Saturday, program activities included mathematics and scientific reasoning skills, statistical concepts, data literacy and analysis, and the exploration of math-related careers. Mentors were responsible for designing and teaching mini skill-building lessons for their team of girls based on the results of mathematics skills pre-tests for their individual group of girls. A typical program day began at 9:00 a.m., concluded at about 2:30 p.m., and incorporated both whole group and teamwork. The course of study for the 
10-week session reflected the vision for school mathematics articulated in the Principles and Standards for School Mathematics (National Council of Teachers of Mathematics, 2000) for data analysis, communication, and representation for grades 6-8 (see Figure 1).

The program established a collaborative environment through the use of small groups and single-sex participants, that is, only girls (the university mentors could be female or male). The seventh-grade girls and mentors worked in research teams that comprised two university students and three to four seventh graders. Teams worked together to complete a research project investigating a topic of interest. The project included designing a survey, collecting data, and using descriptive and inferential statistical techniques. The program organizers also brought senior-level researchers and female scientists to talk with girls and provide role models and introductions to career options.

\section{Method}

\section{Participants}

Seventh-grade girls. In the first two terms of the program (academic year 2002-2003), 74 seventh-grade girls participated; 71 girls completed the program. Approximately $70 \%$ came from urban public schools, while $30 \%$ attended suburban or private schools. In terms of race-ethnicity, 38 (51\%) were African American, 15 (20\%) were Caucasian, 5 (6.8\%) were Asian American, 1 (1\%) was Latina, and 15 (20\%) were self-identified multiracial; data were incomplete for 2 girls. Among the 15 girls reporting multiple ethnic backgrounds, the majority reported some African American background.

Although it was suggested that girls interested in participating should have at least a B-average, no corroboration of the self-reported grades was obtained. Instead, the results of the 32-item mathematics skills test given pre-program indicated that girls entered the program with a wide range of skill levels. The girls' scores on the pre-test ranged from 3 to 24 items correct, which prompted us to disaggregate the data by entry-level skills.

Group data for the first year of implementation was disaggregated by pre-test data into three equivalently numbered categories: low, middle, and high. Girls with scores below 8.5 were assigned to the "low" group $(n=$ 24), girls with scores between 9 and 13.5 were assigned to the "middle" group $(n=23)$, and girls with scores of 14 or above were assigned to the "high" group $(n=24)$. There was also evidence of disparity in the school settings from which girls came in terms of access to resources and the curriculum objectives. 
University student mentors. Thirty-five university students participated in the service-learning courses offered in the academic year. Twenty of the mentors were enrolled in a teacher preparation program; fifteen were enrolled in liberal arts courses. Two teacher candidates were male, the others were female; all fifteen liberal arts students were female. The teacher candidates were primarily graduate students, with a median age of 27 years $(M=30$ years). The majority of the liberal arts students were undergraduates, with a median age of 21.5 years ( $M=24$ years). The mentors differed by ethnic identity: $70 \%$ of the teacher candidates self-identified themselves as White, 5\% African American, 10\% Arab American, $10 \%$ multiracial, and 5\% other; $33 \%$ of the liberal arts students identified as White, 33\% African American, 20\% multiracial, and 13\% Asian American.

The majority of the teacher candidates were graduate students seeking a career change and entering mathematics education; on the other hand, the majority of the liberal arts students were traditional-age undergraduate students in psychology and/or women's studies. All of the university student mentors had prerequisite statistics or mathematics classes, and each mentor group participated in an orientation session prior to the beginning of the program. Mentors also attended a weekly seminar at their respective universities in addition to the Saturday sessions with the girls.

The interaction of university students from multiple disciplines extended the meaning of community. Thus, community service learning involved not only partnering university student mentors with the middle school girls but also partnering graduate students with undergraduates crossing university connections, disciplinary boundaries, age, and social class lines.

\section{Measures}

Mathematical confidence and skills. The subscale for confidence was taken from the Fennema-Sherman Mathematics Attitudes Scales and was included in the pre-program survey administered to the 7th grade girls. This subscale consists of 5 items with which students could indicate their agreement or disagreement, from a range of 1 (strongly disagree) to 5 (strongly agree). Sample statements include "I can get good grades in mathematics" and "I think I can handle more difficult mathematics."

A mathematics skills assessment measure was constructed with questions modeled after the statistics and probability items on the eighth-grade mathematics educational test administered by the Michigan State Department of Education. The skills assessed included interpreting graphical rep- 
resentations and demonstrating knowledge and application of descriptive statistics. Items measuring students' understanding of rational number concepts were also included. This measure consisted of 32 items ranging in level of difficulty from easy to difficult.

Additional data were collected documenting the girls' confidence from the participants' journal entries during the program and from the post-program survey completed by the participants' parents. Parents responded to both open-ended and scaled response questions at the closing reception. Qualitative data were subjected to textual content analysis using NVivo software, whereby evolving "nodes" were used to mark relevant concepts based on participant responses for each question.

Educational aspirations and career goals. Both open-ended and structured questions about career goals and educational aspirations were constructed to determine how the students felt about education and careers before and after participating in the program. Students were asked to estimate the number of years and degrees they might pursue as well as specific career goals. For the educational aspirations, goals were scaled from 1 to 9 , with scores from 1 to 5 indicating grade school to high school graduation and scores of 6 to 9 designating 2-year college graduation to professional degrees.

Mentoring and program perceptions. Girls were asked to write journal entries in which they answered clusters of open-ended questions regarding aspects of the mentoring relationship and about their program experience. Entries were collected four times during the 10-week program. In the journal prompts, participants were asked to reflect upon the activities, the mentors, and group interactions.

\section{Procedures}

Girls were recruited directly through contacts with teachers, ministers, community groups, and university newsletters. The program required interested girls to submit an application with a brief personal statement and a recommendation from a teacher or another adult. On entry into the program, girls were given a mathematics skills assessment test and completed an attitudinal survey about school, career, and educational aspirations as well as other issues. A research assistant assigned to the project administered the instruments. The seventh-grade girls completed pre- and postprogram surveys and answered journaling prompts throughout the program. Informed consent was obtained from all participants (girls, parents/guardians, and mentors) during the program orientation. 
Repeated-measures analyses of variance were conducted on the Fennema-Sherman mathematics confidence subscale, questions regarding educational aspirations, and scores on the mathematics competence assessment, with time as the within-subject factor.

\section{Results}

\section{Mathematical Confidence and Skill}

The analysis of Fennema-Sherman subscale of mathematical confidence supported the hypothesis that the program would increase girls' confidence in mathematics. The data indicated that there was a significant increase from pre-test to post-test: $M=4.05$ and $4.14, S D=.59$ and .57 , respectively, $F(1,73)=4.36, p<.05$.

The mathematics skill assessment given pre- and post-test also supported the hypothesis predicting improvement in mathematical skill level. The girls demonstrated an improvement in mathematical skills; their scores on the mathematical skill measure constructed from eighth-gradelevel mathematics problems increased almost 4 points. This pre- to posttest increase was significant: $M=11.8$ and $15.14, S D=5.34$ and 6.51 , respectively; $F(1,70)=45.5, p<.000$. In addition to the significant increase across participants, data disaggregated by groups (low, medium, and high) provide evidence that girls at each entry level demonstrated gains during the program.

Box plots graphically represent the change in the distribution of preand post-program scores for each group and show both an upward shift in the range of scores and an increase in median scores across all levels. Students in the top two quartiles at each level also showed increased skill levels. For example, for students who were assigned to the "low" group based on their pre-test scores, the median post-program score increased from 6.5 to 9.5 , which means that more than $50 \%$ of the girls achieved a score that was above the maximum pre-test score (8.5) for that group (see Figures 2-4).

\section{Educational Aspirations and Career Goals}

Pre- and post-test program comparisons showed no change in educational and career aspirations. The failure to find an increase in aspiration is due to a ceiling effect caused by high pre-test scores; the girls' mean pre-test score was 7.89 (a score of 7 indicated 4-year college or more); the posttest mean score was 8.01 (a score of 8 indicated a postgraduate degree); $F(1,71)=.61, p=.44$. 


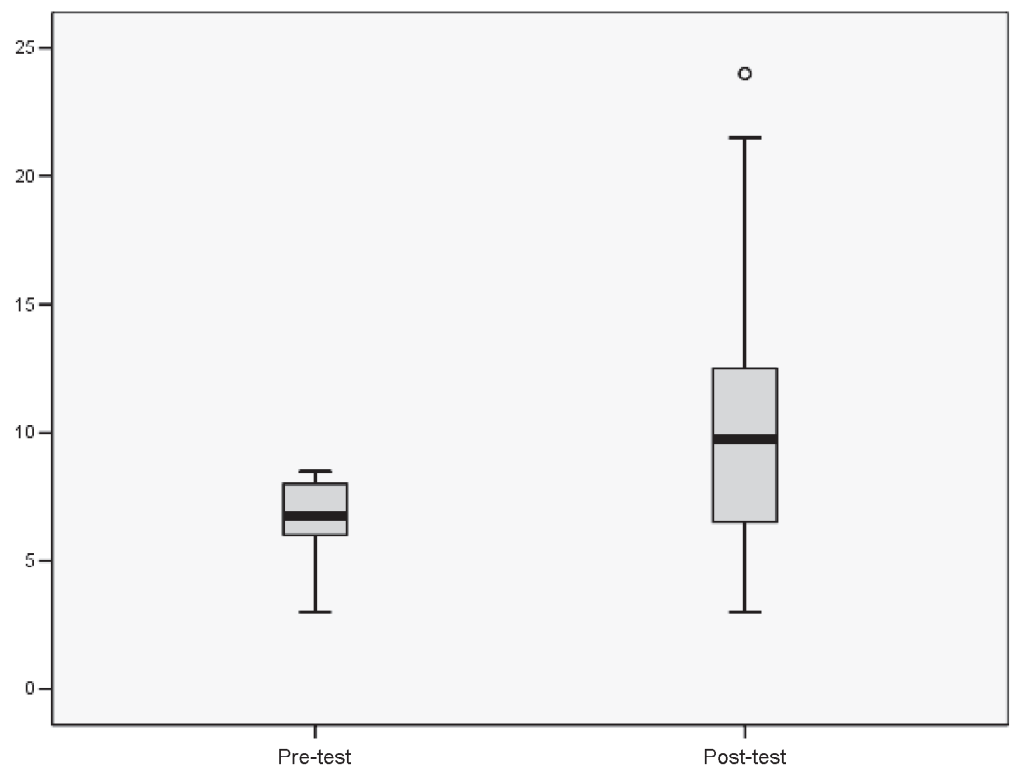

Figure 2. Pre- and post-program test scores for low group

The girls' journal reports also indicate that the commitment to education and career goals expressed by participants pre-program was reinforced through the GO-GIRL program. In particular, some girls wrote that they were thinking more about their future. One girl wrote, "I'm not really sure what I want to be, but I really want to do something that involves math and science." Another girl echoed this commitment to new educational goals: "The activity where you see what your future job is and stuff like that really helped me understand what my future might be like."

On the post-program survey, parents reported not only that the program increased their daughters' perception of their mathematical abilities and confidence in mathematics and science but also that they believe the GO-GIRL experience translated to their daughters' ongoing academic success. When specifically asked about their daughters' mathematics grades, parents reported that their daughters were receiving A's and B's and some C's in their mathematics classes; these grade reports represent either no change or improvement in school performance. 


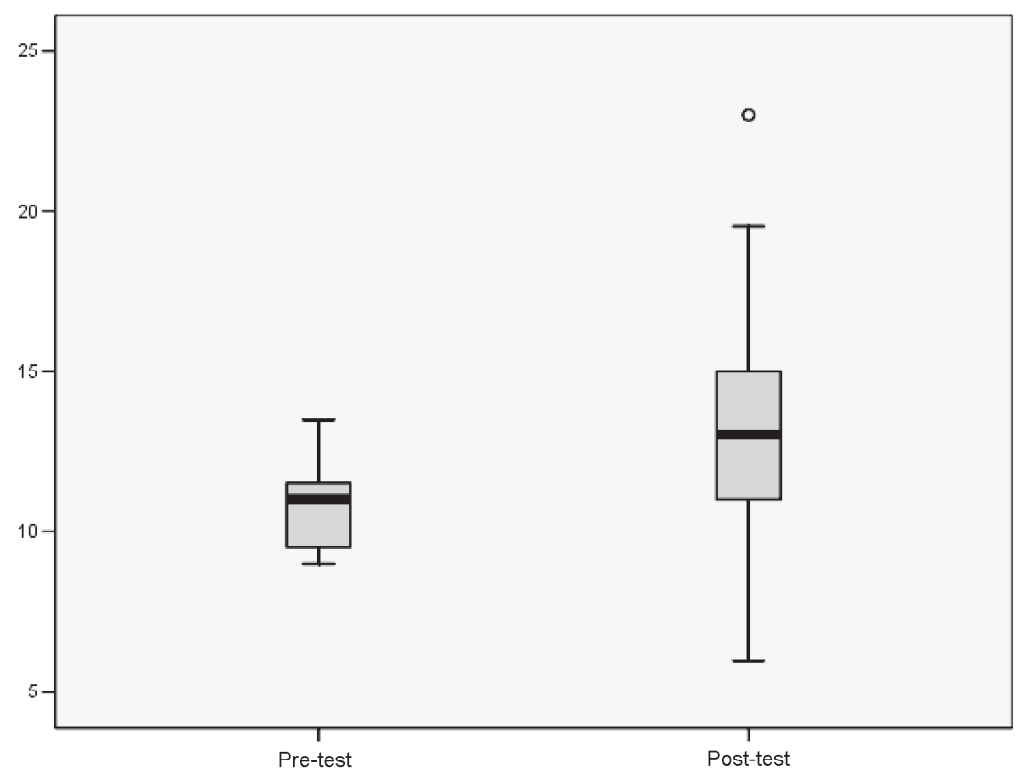

Figure 3. Pre- and post-program test scores for middle group

\section{Benefits of Mentors and Small Groups}

Journal responses support our expectations that the mentoring relationship contributed to increased mathematics confidence and competence for the girls. Participants identified both the instrumental (i.e., specific skill building) and the relational (i.e., social and emotional) mentoring aspects of the program. They identified their mentors as friends $(81.1 \%)$ and as teachers $(25.7 \%)$.

Content analysis of the journals further documents that participants viewed their mentors in an instrumental role, with $95.9 \%$ of participants reporting that their mentors provided academic assistance (help with mathematics skills, technology use), and also viewed them in a relational role, with $41.9 \%$ reporting that their mentors provided social support (advice about school, friendship, preparing for college, and careers) and $9.5 \%$ reporting that their mentors also provided emotional support (just listening to girls, sharing of personal feelings). Here are some comments from the girls' journals:

- "My mentors help me by answering my questions, also by discussing the question so that we have a good understanding of what they are 


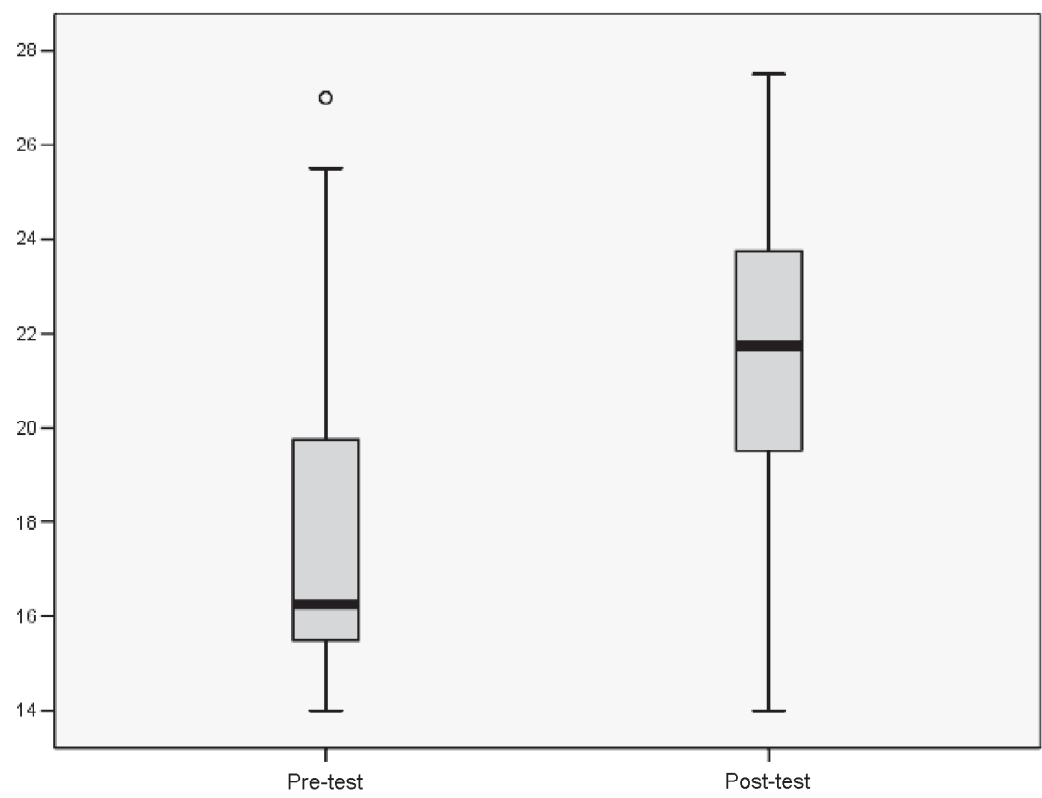

Figure 4. Pre- and post-program test scores for high group

asking. They also help by listening to our opinions and giving us theirs so that we know each other's point of view."

- "I've learned that there are SO many careers out there for me! A lot of them have to do with mathematics but if you can do well in school then you have a lifetime of choices waiting for you!"

- "[Mentors] listen to us when we need someone to talk to."

Journal responses also indicate that participants were overwhelmingly positive about the small collaborative group-learning environment, with 67 of the $74(90.5 \%)$ participants characterizing it as beneficial. Three major themes emerged related to perceived benefits: it fosters equal participation, encourages the sharing of opinions and ideas, and allows girls to learn from each other.

\section{Discussion}

The GO-GIRL program, designed to address the failure of girls to persist in mathematics and to pursue math-related careers, offers promise for success. Using elements that have been shown effective in other settingsthat is, single-sex participants (Haag, 1998; V. Lee \& Marks, 1990), small 
learning groups (Fennema \& Peterson, 1985), and role models and mentoring (Dubois, 2002; Freedman, 1993; Katayama, 2001; Philip \& Hendry, 2000; Sullivan, 1996) — this implementation program provided training and support for the development of girls' mathematics skills, scientific thinking, and career planning.

Pre- and post-program comparisons indicate that GO-GIRL had a positive impact on participants' confidence in their ability to do well in mathematics. The positive relation between confidence and performance has been demonstrated in numerous studies (Eccles et al., 1983; National Science Foundation, 2000; Siegle \& Reis, 1995). Similarly, there is also a positive relation between success and future attributions or expectation of success (Eccles, 1987). The GO-GIRL program was also effective in supporting girls' successful completion of a sophisticated project and, indeed, in increasing their mathematical skill set in the relatively short time frame of 10 weeks. This is encouraging, since the middle school years are a pivotal point for many girls and often the beginning of downward spiral of confidence and competence.

The program did not significantly increase the level of girls' educational or career aspirations. This appears to be a function of the high level that program participants already demonstrated on the pre-test measures. However, the girls' journal reports do suggest that the program activities and the experience of the close relationship with college student mentors, as well as the opportunity to meet with researchers who served as potential role models, supported the girls' high aspirations and encouraged them in the desired directions.

The qualitative data also serve to illuminate the fact that the program influenced participants' knowledge of and appreciation for "college life." Although the participants in the program already aspired to achieve a college education, they gained insights into what the college experience might entail and became more knowledgeable about the actual college experience. For example, one girl's response indicates that she gained awareness of university course offerings: "I have learned a lot from my mentors because they talk about their majors and what they do, why they like it." Other girls similarly voiced the notion that the program experience had provided information about the college: "I learned some more ways of how colleges function"; "Learning about State U. was helpful, cause I knew absolutely nothing about their college"; and "I learned a lot [in GOGIRL] and college is a big step and I am glad to take it."

There was little to no attrition of girls from the program, and the weekly attendance was consistently high. The only external incentive provided for participation in the program was that the girls who completed 
the program received a high-school-level graphing calculator. Comments and journal entries from the girls and the mentors indicate that the commitment and persistence demonstrated by the girls was directly related to the sense of community that developed in the research teams over the course of the program. This closeness carried over after the program was completed, as most girls expressed a desire to remain in contact with their team members and mentors.

The influence of the mentors cannot be overstated; literally every girl mentioned, in one journal comment or another, the positive impact of the relationship with the college mentors. While not measured through either quantitative or qualitative strategies, it seems meaningful to report that at the closing meeting of each term, the close bond that had developed between mentors and girls was clearly in evidence. As described in the journals, the mentors served both instrumental and relational roles that were valued by the girls. Young adolescents rarely have the opportunity to interact with adults who have time, energy, and interest in talking with them and assisting them in ways important to them. The exchanges, of course, were also valuable for the university students, who were connected to a diverse group of youngsters in ways that were meaningful to their subject of study.

Although there are limitations to drawing conclusions from a naturalistic study without the benefit of a comparison sample, the findings from the participants in this program appear consistent with results obtained in research models. We also have confidence in our conclusions given that findings were similar across 2 years and 4 cohorts of girls. The post-program interviews with parents and girls suggest that participation in GOGIRL had a positive effect on interpersonal and communication skills. In fact, many of the GO-GIRL participants remarked that the program helped them feel more confident about speaking up in classes as well as talking with their teachers. It is our continued responsibility to explore and research the effects of intervention programs that encourage the voices of young females from ethnic minority backgrounds to be heard in classrooms of today and in quantitative careers of tomorrow.

\section{References}

Bae, Y., Smith, T. M., Pratt, R., \& National Center for Education Statistics. (1997). Women in mathematics and science. Washington, DC: National Center for Education Statistics U.S. Dept. of Education Office of Educational Research and Improvement. For sale by the U.S. G.P.O. Supt. of Docs.

Brush, L. R. (1979). Avoidance of science and stereotypes of scientists. Journal of Research in Science Teaching, 16(3), 237-241. 
Campbell, P. B. (1995). Redefining the "girl problem in mathematics." In W. G. Secada, E. Fennema, \& L. B. Adajian (Eds.), New directions for equity in mathematics education (pp. 225-241). New York: Cambridge University Press.

Clewell, B. C., Anderson, B. T., \& Thorpe, M. E. (1992). Breaking the barriers: Helping female and minority students succeed in mathematics and science. San Francisco, CA: Jossey-Bass.

College Board Online. (1997). "Table 18." Princeton, NJ: Educational Testing Service.

Cooper, J., Hall, J., \& Huff, C. (1991). Situational stress as a consequence of sexstereotyped software. Personality and Social Psychology Bulletin, 16, 419-429.

DuBois, D. (2002). Life imitates (and informs) meta-analysis: A participatory approach to increasing understanding of effective youth mentoring practices. Journal of Prevention and Intervention in the Community: Special Issue: Community interventions to create change in children, 24, 3-15.

Eccles, J. S. (1984). Sex differences in mathematics participation. In M. Steinkamp \& M. Maehr (Eds.), Women in science (pp. 93-138). Greenwich, CT: JAI Press.

Eccles, J. S. (1987). Gender roles and women's achievement-related decisions. Psychology of Women Quarterly, 11, 135-171.

Eccles, J. S. (1997). User-friendly science and mathematics: Can it interest girls and minorities in breaking through the middle school wall? In D. Johnson (Ed.), Minorities and girls in school: Effects on achievement and performance (pp. 65-104). Thousand Oaks, CA: Sage.

Eccles, J. S., Adler, T. F., Futterman, R., Goff, S. B., Kaczala, C. M., Meece, J. L., \& Midgley, C. M. (1983). Expectancies, values, and academic behaviors. In J. T. Spence (Ed.), Perspectives on achievement and achievement motivation (pp. 75-146). San Francisco: Freeman.

Fennema, E. (1996). Mathematics, gender, and research. In G. Hanna (Ed.), Toward gender equity in mathematics education (pp. 9-26). Dordrecht: Kluwer.

Fennema, E., \& Peterson, P. L. (1985). Autonomous learning behavior: A possible explanation of gender-related differences in mathematics. In L. C. Wilkinson \& C. B. Marrett (Eds.), Gender-related differences in classroom interactions (pp. 17-35), New York: Academic Press.

Freedman, M. (1993). The kindness of strangers: Adult mentors, urban youth, and the new voluntarism. San Francisco: Jossey-Bass.

Gavin, K., \& Reis, S. (2003). Helping teachers to encourage talented girls in mathematics. Gifted Child Today, 26(1), 32-44.

Gilbert, M. C. (1996). Attributional patterns and perceptions of math and science among fifth-grade through seventh-grade girls and boys. Sex Roles, 35(7-8), 489-506. 
Haag, P. (1998). Single-sex education in grades K-12: What does the research tell us? In Separated by sex: A critical look at single-sex education for girls. Washington, DC: American Association of University Women Educational Foundation.

Hill, S. T. (2002). Science and engineering degrees: 1966-2000 (No. NSF 02327). Arlington, VA: National Science Foundation Division of Resources Statistics.

Hoffmann, L., \& Haussler, P. (1998). An intervention project promoting girls' and boys' interest in physics. Paper presented at the Seoul Conference on Interest in Gender, Kiel.

Kardash, C. A. M. (2000). Evaluation of undergraduate research experience: Perceptions of undergraduate interns and their faculty mentors. Journal of Educational Psychology, 92, 191-201.

Katayama, A. D.(2001). Bi-modal instructional practices in educational psychology: Mentoring and traditional instruction. Journal of Instructional Psychology, 28, 171-177.

Kota, S. (2001). Affect and problem solving performance: Modeling relationships. Dissertation Abstracts International Section A: Humanities and Social Sciences, 61(10-A), 3931.

Kusimo, P., Carter, C., \& Keyes, M. (1999). I'd like to go to Harvard but I don't know where it is: Bridging the gap between reality and dreams for adolescent African American girls. Paper presented at the Annual Meeting of the American Research Association, Montreal, Quebec, Canada. (ERIC Document Reproduction Service No. ED439205)

Leder, G. C. (1992). Mathematics and gender: Changing perspectives. In D. A. Grouws (Ed.), Handbook of research on mathematics teaching and learning (pp. 597-622). New York: Macmillan.

Lee, J. D. (1998). Which kids can "become" scientists? Effects of gender, selfconcepts, and perceptions of scientists. Social Psychology Quarterly, 61(3), 199-219.

Lee, V., \& Marks, H. (1990). Sustained effects of the single-sex secondary school experience on attitudes, behaviors, and values in college. Journal of Educational Psychology, 82(3), 578-592.

National Council of Teachers of Mathematics. (2000). Principles and standards for school mathematics. Reston, VA: National Council of Teachers of Mathematics.

National Research Council. (1989). Everybody counts: A report to the nation on the future of mathematics education. Washington, DC: National Academy Press.

National Science Board. (2003). The science and engineering workforce: Realizing America's potential (NSB Publication No. nsb03-69). Washington, DC: National Science Foundation. 
National Science Foundation. (2000). Learning curve: Prefatory report: What we are discovering about U.S. science and mathematics education (NSF Publication No. nsf9653). Washington, DC: National Science Foundation.

National Science Foundation. (2002). Women and science: Celebrating achievements, charting challenges (NSF Publication No. nsf9775). Washington, DC: National Science Foundation.

Philip, K., \& Hendry, L. B. (2000). Making sense of mentoring or mentoring making sense? Reflections on the mentoring process by adult mentors with young people. Journal of Community and Applied Social Psychology, 10, 211-223.

Rebhorn, L., \& Miles, D. (1999). High-stakes testing: Barrier to gifted girls in mathematics and science. School Science and Mathematics, 99(6), 313-19.

Reid, P. T., \& Stewart, A. J. (2002). Using Math: Girls Investigate Real Life (UMGIRL): A report on the 2001 summer program and the 2001/2002 follow up activities. Ann Arbor: University of Michigan Institute for Research on Women and Gender.

Reis, S. (1987). We can't change what we don't recognize: Understanding the special needs of gifted females. Gifted Child Quarterly, 31(2), 83-89.

Reis, S., \& Callahan, C. (1989). Gifted females: They've come a long way-or have they? Journal for the Education of the Gifted, 12, 99-117.

Riley, R. W. (1997). In math and college-going, middle school makes all the difference. Middle School Journal, 29(2), 3-7.

Siegle, D., \& Reis, S. M. (1995). Gender equity: Still knocking at the classroom door. Educational Leadership, 56(7), 22-26.

Sprinthall, N. A., \& Scott, J. R. (1989). Promoting psychological development, math achievement, and success attribution of female students through deliberate psychological education. Journal of Counseling Psychology, 36, 440-446.

Sullivan, A. M. (1996). From mentor to muse: Recasting the role of women in relationship with urban adolescent girls. In N. Way (Ed.), Urban girls: Resisting stereotypes, creating identities. New York: New York University Press.

Wigfield, A., \& Eccles, J. (2002). The development of competence beliefs, expectations for success, and achievement values from childhood to adolescence. In A. Wigfield \& J. Eccles (Eds.), Development of achievement motivation (pp. 91-120). New York: Academic Press. 